\title{
Avaliação da mutagênese e genotoxicidade em Eigenmannia virescens (Teleostei: Gymnotiformes) expostos ao benzeno
}

\author{
Augusto BÜCKER ${ }^{1}$, Wanderson CARVALHO², José Antonio ALVES-GOMES 3
}

\begin{abstract}
RESUMO
Os efeitos de substâncias genotóxicas sobre o genoma de peixes tem sido objeto de muitos estudos, sobretudo daqueles que buscam estabelecer a resposta dos genes aos estímulos ambientais. O presente trabalho teve como objetivo realizar um estudo sobre mutagenicidade e genotoxicidade em peixes elétricos da espécie Eingenmannia virescens, pela exposição ao benzeno (50ppm), utilizando as técnicas da Frequêencia de Micronúcleos (MNs) e o Ensaio do Cometa. Foram coletadas amostras do sangue de dez peixes em diferentes tempos de exposição: $\mathrm{T}_{0}, 24 \mathrm{~h}, 48 \mathrm{~h}, 72 \mathrm{~h}, 96 \mathrm{~h} \mathrm{e} 360 \mathrm{~h}$ (15 dias). Para a análise das lâminas no Teste do MN, foram contadas 1.000 células e estipulada a frequiência de ocorrência de MNs. Para análise do Ensaio do Cometa a contagem foi feita estipulando quatro classes de danos: I - II - III - IV, e para a análise estatística foram atribuídos valores numéricos (ranques) de 0 a 3 , respectivamente, verificando diferenças significativas para a soma dos ranques em todos os tempos de exposição em relação ao $\mathrm{T}_{0}$. No Teste do Micronúcleo não foi possível detectar efeitos mutagênicos significativos nos eritrócitos analisados. No entanto, para o Ensaio do Cometa os resultados sugerem ação genotóxica do benzeno, devido a um aumento gradual no número de células com maiores classes de danos de acordo com maior tempo de exposição, indicando um efeito tempo-dependente. Estes resultados sugerem maior sensibilidade do Ensaio do Cometa que o Teste do MN.
\end{abstract}

PALAVRAS-CHAVE

Teste do Micronúcleo; Ensaio do Cometa; peixes elétricos; eritrócitos

\section{Avaliation of mutagenicity and gentotoxicity in Eigenmannia virescens (Teleostei: Gymnotiformes) exposed to benzene}

\begin{abstract}
The effects of genotoxic substances on fishes genome have been object of many studies, especially those which attempt to establish the responses of genes to environmental stimulus. The objective of this study was to evaluate the mutagenicity and genotoxicity in electric fishes of species Eingenmannia virescens, under to benzene exposure (50ppm), utilizing Micronuclei Test (MNs) and Comet Assay techniques. Ten fish blood samples were collected in different times of exposure: $T_{0,} 24 \mathrm{~h}, 48 \mathrm{~h}, 72 \mathrm{~h}, 96 \mathrm{~h}$ and $360 \mathrm{~h}$ (15 days). To determine the frequency of $M \mathrm{Ns}_{\mathrm{s}}$, 1.000 cells per microscopical slides were counted. For the Comet Assay analysis, four damage classes were defined: I-II-III-IV, and for the statistic analysis number values (ranks) from 0 to 3 were assigned for each class. The sum of ranks (values) for all times of exposure was compared to $T_{0}$ and these differences were statistically analyzed. On Micronuclei Test demonstrated do not possible detect significant mutagenic effects in the erythrocytes analyzed. On the other hand, for the Comet Assay, the results suggested genotoxic action of benzene, proper the gradual increase of number of cells with greatest damage class with the greatest of exposure time, indicating an effect time-dependent. These results suggested the most sensibility for the Comet Assay like Micronuclei Test.
\end{abstract}

\section{KEY-WORDS}

Micronucleus test; Comet assay; electric fishes; erythrocytes; 


\section{INTRODUÇÃO}

Durante as últizmas três décadas, a comunidade científica e agências regulatórias têm tomado consciência sobre os impactos ambientais sobre a saúde humana e a sustentabilidade dos ecossistemas (Bickham et al., 2000). No Brasil, os testes de ecogenotoxicidade têm sido empregados desde a década de 80 , para avaliaçōes ambientais (Valent, 1998). Também nos últimos 20 anos, tem-se verificado que os testes de toxicidade com organismos aquáticos constituem uma ferramenta efetiva para avaliação de efeitos de poluentes sobre os organismos vivos, para avaliação de risco/periculosidade de agentes químicos, no monitoramento da qualidade da água e no estabelecimento de limites permissíveis de lançamento de efluentes líquidos nos corpos hídricos (Zagatto, 1998).

É de suma importância que se procure estabelecer protocolos mais eficientes e rápidos para uma análise in situ sobre as condiçōes ambientais em ambientes aquáticos. A importância está em se evitar que percam evidências somente detectadas no ambiente, à exemplo de organofosforados, que não persistem nas amostras durante o tempo entre a coleta no rio e sua análise em laboratório (Shugart et al.,1989).

O Conselho Nacional do Meio Ambiente - CONAMA (2000) reconhece a insuficiência e ineficácia de respostas diante aos problemas ambientais com hidrocarbonetos e, em alguns casos, a dificuldade de implantar as açōes necessárias para evitar possíveis problemas ambientais. Há registros de que o benzeno $\left(\mathrm{C}_{6} \mathrm{H}_{6}\right)$ causa câncer (leucemia), sendo classificado no Grupo 1 pela Agência Internacional de Pesquisas em Câncer, como cancerígeno para humanos (IARC, 2003).

Análises de genotoxicidade são executadas em bioindicadores de toxicidade, ou de efeitos adversos, que podem ser definidos como: "qualquer resposta biológica, ao nível do indivíduo ou a um nível inferior, a um ambiente químico, que traduz a exposição a esse ambiente"; alterações bioquímicas, fisiológicas e comportamentais incluem-se nesta (W.H.O., 1993; Capela, 2001).

A Ordem dos peixes Gymnotiformes tem uma distribuição Neotropical que compreende cerca de 100 espécies, divididas em sete famílias (Alves-Gomes et al., 1995). Gymnotiformes são popularmente conhecidos como "peixes elétricos" por terem a capacidade de produzir corrente elétrica alternada, por seu tecido especializado, o órgão elétrico (Chagas \& Carvalho, 1961; Bennett, 1971).

As características biofísicas (forma de onda, amplitude e taxa de repetição) da Descarga do Órgão Elétrico (DOE) estão diretamente relacionadas com a composição físico-química da água onde o peixe se encontra (Bullock et al., 1979; Rossoni, 2005). A presença de elementos tóxicos na água causa uma alteração nas DOE's tanto pela mudança da condutividade da água, quanto pela ação direta do poluente no metabolismo do peixe. Cada espécie possui uma DOE própria, apesar disso, os gymnotiformes podem ser subdivididos em dois grandes grupos, de acordo com o tipo de descarga: peixes pulsadores e peixes onduladores (Alves-Gomes, 1997).

Gymnotiformes estão sendo utilizados como organismos de biomonitoramento no Laboratório de Fisiologia Comportamental (LFC/INPA). O peixe elétrico Eingenmannia virescens, família Eingenmanniidae, é um gymnotiforme do tipo ondulador que apresenta freqüência e amplitude da DOE relativamente constantes (Kramer, 1999), e foi escolhido para este estudo pela abundância de exemplares e facilidade de captura, o que possibilita uma continuidade em estudos de monitoramento ambiental.

Atualmente uma das metodologias utilizadas para avaliar danos causados por substâncias xenobióticas nos organismos é o Teste do Micronúcleo (MN), inicialmente desenvolvido em eritrócitos de medula óssea de camundongos (Schimid, 1976). Esse tipo de teste tem sido recomendado para estudos de biomonitoramento ambiental, principalmente por sua capacidade de detectar agentes clastogênicos (quebra de cromossomos), e de agentes aneugênicos (segregação cromossômica anormal) requerendo, no entanto, proliferação celular para a observação do biomarcador de efeito. (Fenech, 2000; Ribeiro et al., 2003).

Em estudos realizados por Bücker \& Conceição (2004), o Teste do MN foi utilizado para biomonitoramento ecotoxicológico nos Rios Itajaí-Açú e Itajaí-Mirim, no Estado de Santa Catarina-BR, para verificar o grau de poluição através de sua resistência até 10 dias em exposição às águas dos Rios, onde o biomardador utilizado foi o peixe tilápia (Oreochromis niloticus). $\mathrm{Na}$ bacia Amazônica o teste $\mathrm{MN}$ foi utilizado para avaliação mutagênica de altas concentraçôes de mercúrio encontradas no Rio Madeira, examinando-se três espécies comercialmente importantes da regiāo (Prochilodus nigricans, Curimatã; Mylossoma duriventris, Pacu branco; e Hoplias malabaricus, Traíra), onde se mostrou ação genotóxica significativa quando comparado ao controle negativo (área não poluída) utilizando-se peixes do Rio Solimões (Porto et al., 2005).

Outro teste de avaliação genotóxica utilizado neste estudo foi o Ensaio do Cometa (eletroforese em gel de células individuais), com uma ampla utilização para se testar agentes genotóxicos de dejetos industriais, domésticos e agrícolas, indução de danos e reparo no DNA, biomonitoramento de populações expostas, bem como em aplicaçôes clínicas (White \& Rasmussen, 1998; Hartmann et al., 2003). As vantagens do Ensaio do Cometa incluem a sua simplicidade, rápida performance e sua alta sensibilidade para vários tipos de danos no DNA (Da Silva et al., 2003; Gonçalves et al., 2003).

Portanto, o objetivo do presente estudo foi desenvolver um protocolo de biomonitoramento utilizando as técnicas Teste do Micronúcleo e o Ensaio do Cometa como biomarcadores de efeitos da ação xenobiótica do benzeno na água. 


\section{MATERIAL E MÉTODOS}

\section{DESENHO EXPERIMENTAL}

Para este presente estudo, foi realizado um bioensaio com peixes elétricos da espécie Eingenmannia virescens, coletados na

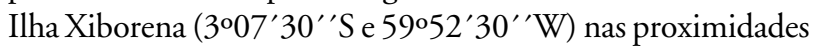
de Manaus-AM, nos meses de Abril e Maio (período de cheia dos rios na Amazônia). 10 exemplares foram aclimatados por 7 dias em um aquário contendo até 40 litros de água proveniente do poço artesiano do INPA, com aeração constante e a temperatura ambiente de $29 \pm 2^{\circ} \mathrm{C}$, e pH $5,5 \pm 2$; para posterior exposição a concentração de $50 \mathrm{ppm}$ de benzeno $\left(\mathrm{C}_{6} \mathrm{H}_{6}\right)$, não sendo renovada a água do experimento. As amostras de sangue para o Ensaio do Cometa e o Teste do MN foram coletadas nos tempos: $\mathrm{T}_{0}, 24 \mathrm{~h}, 48 \mathrm{~h}, 72 \mathrm{~h}$, 96h e $360 \mathrm{~h}$ (15 dias).

\section{TESTE DO MICRONÚCLEO}

O sangue foi coletado e gotejado sobre uma lâmina para ser feito o esfregaço, e esperado o período de "overnight" para secagem do material. A lâmina foi submetida a um banho de 15 minutos em Metanol P.A. (100\%) para a fixação. Em seguida, foi feita uma lavagem com água destilada corando-se a lâmina por 40 minutos em Giemsa 5\%; lavada posteriormente com água destilada e seca ao ar, em temperatura ambiente. Depois de seco, o material foi observado em microscópio óptico para contagem

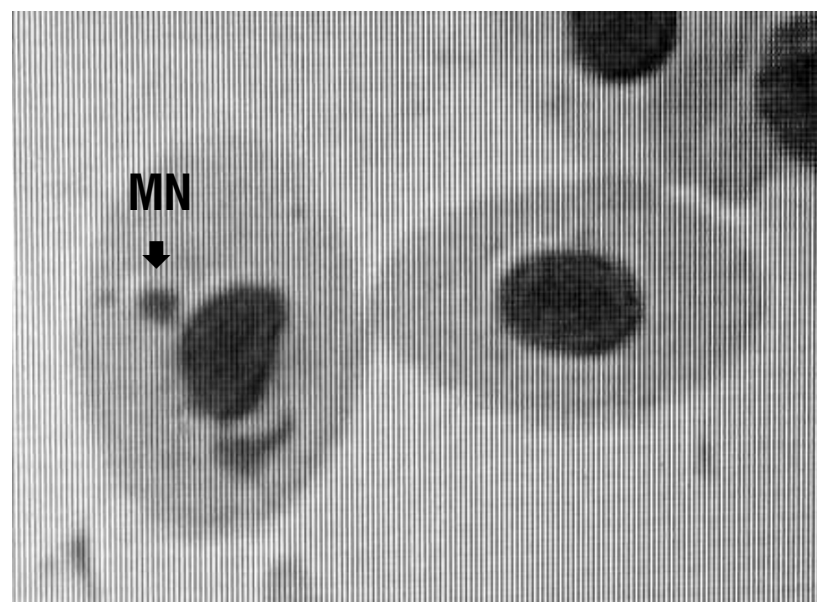

Figura 1 - Eritrócito de peixe elétrico E. virescens com Micronúcleo. dos micronúcleos presentes e posterior análise dos dados. A análise citogenética foi realizada em microscópio óptico em resolução 1000x (Figura 1), com contagem de 1000 células por lâmina (Campana et al., 1999; Grisolia, 2002). Os MNs foram identificados seguindo o critério proposto por Fenech et al. (2003). A comparação estatística entre os grupos controle e tratado foi feita utilizando o teste não-paramétrico Teste-U de MannWhitney $(\mathrm{p}<0.05)$.

\section{ENSAIO DO COMETA}

A análise foi realizada de acordo com o protocolo descrito por Singh et al. (1988), com algumas modificações. Foram utilizadas lâminas previamente cobertas com agarose normal $(0,5 \% \mathrm{p} / \mathrm{v}$ em tampão PBS). O sangue foi coletado e $10 \mathrm{ml}$ deste sangue foi misturado com $75 \mu$ de agarose "low melting point" (LMP), para ser coberto pela segunda camada de $75 \mu$ l de agarose LMP, e incubado em tampão de Lise (2,5 M NaCl, $100 \mathrm{mM}$ EDTA, $10 \mathrm{mM}$ Tris, $10 \%$ DMSO, 1\% TRITON X-100, Sarcosina $0,01 \mathrm{M}), \mathrm{pH} 10$, por 1 hora. Posteriormente, as lâminas passaram pelo processo em tampão de Desnaturação $(\mathrm{NaOH} 30 \mathrm{mM}, 1$ mM EDTA) $\mathrm{pH}>13$, pré-resfriado entre $5-8{ }^{\circ} \mathrm{C}$ e incubadas de maneira a cobrir as lâminas, por 10 minutos. A eletroforese transcorreu a $25 \mathrm{~V}$ e $300 \mathrm{~mA}$, por um período de 5 minutos, seguindo critério proposto por Gontijo et al. (2003). Realizandose, logo após, o processo em tampão de Neutralização (Tris 0,4 $\mathrm{M})$, por 10 minutos. As lâminas foram fixadas utilizando etanol $100 \%$ e armazenadas no escuro à temperatura ambiente. Para a análise em microscópio de epifluorescência, as lâminas foram coradas no momento da análise com o corante Alaranjado de Acridina $(3 \mu \mathrm{g} / \mathrm{ml})$.

Para as análises estatísticas dos dados, foi utilizado o teste não-paramétrico Teste-U de Mann-Whitney $(\mathrm{p}<0.01)$, o controle negativo foi estipulado o tempo zero de exposição $\left(\mathrm{T}_{0}\right)$ ao benzeno, se valendo do número basal de danos encontrados nos peixes elétricos antes do tratamento. Foram contadas 100 células por lâmina, estipulando-se previamente quatro Classes de Danos: I - II - III - IV (Figura 2), que para a análise estatística foram atribuídos valores numéricos (Ranques) de 0 a 3 para cada uma das classes, respectivamente. Após a obtenção das freqüências das classes de dano para cada indivíduo, foi calculada a soma dos ranques, para posterior comparação dos resultados entre os tempos de exposição e o $\mathrm{T}_{0}$.
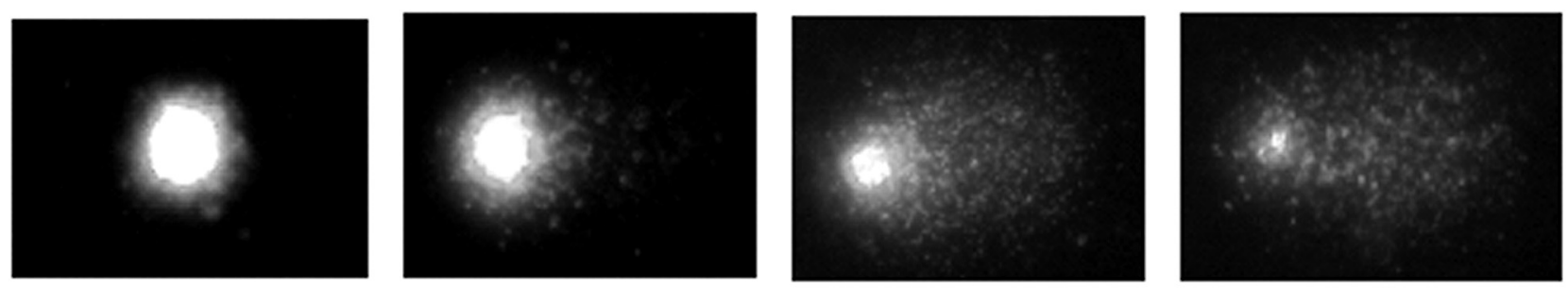

Figura 2 - Segundo 0 critério visual do pesquisador, foram contados os cometas pelas respectivas Classes de danos: I - II - III - IV. 


\section{RESULTADOS}

O Teste do MN foi avaliado comparando-se a freqüência de MNs encontrados nos diferentes tempos de exposição ao benzeno (50 ppm) em relação ao controle negativo (Figura 3). Na tabela 1 são apresentadas as médias e desvios padrão da freqüência de MNs para os diferentes tempos de exposição. Os tempos amostrados não apresentaram diferença significativa para nenhum dos tempos, podendo ser visualizado na média da freqüência de MNs na Figura 4, e confirmado pelo teste não-paramétrico TesteU de Mann-Whitney $(\mathrm{p}<0.05)$.

A tabela 2 mostra o resultado da análise de células de 10 exemplares para o Ensaio do Cometa, onde são apresentadas as médias das classes de dano para cada tempo de exposiçāo, assim como a média da Soma dos Ranques. Na figura 5, é mostrada a relação do número de células encontradas para cada classe de

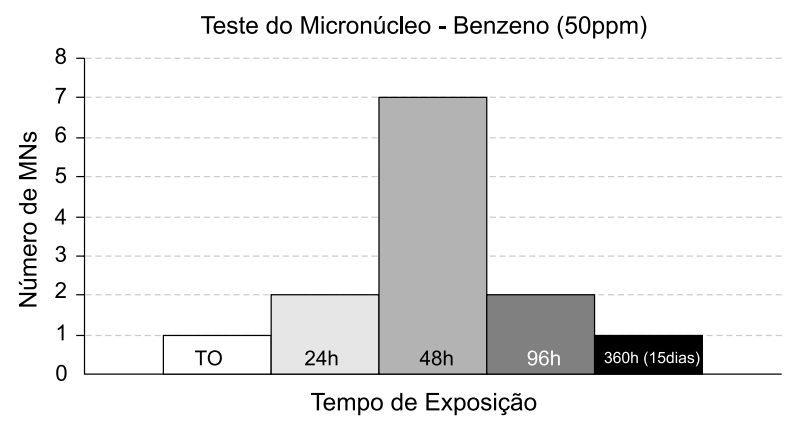

Figura 3 - Freqüência de Micronúcleos para os indivíduos expostos ao tratamento com benzeno $(50 \mathrm{ppm})$ em relação ao tempo de exposição. Onde a maior frequêencia observada foi para 0 tempo de 48 horas e reduzindo a freqüência nos dois tempos seguintes.

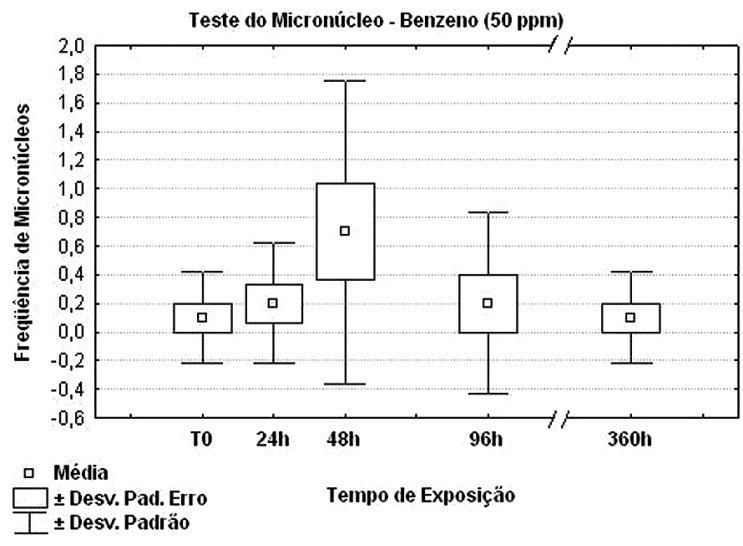

Figura 4 - Médias da Freqüência de Micronúcleos encontrados para $E$. virescens ao tratamento com benzeno (50ppm) nos diferentes tempos de exposição. Não houve diferença significativa para nenhum dos tempos em relação ao controle negativo $\left(T_{0}\right)$ para 0 Teste-U de Mann-Whitney $(p<0,05)$. dano no Ensaio do Cometa, e para os diferentes tempos de exposição ao tratamento com benzeno (50ppm). No tempo $\mathrm{T}_{0}$, ocorre maior número de células para a classe de dano $\mathrm{I}$, tendo em vista que para os níveis seguintes de classes de dano, há uma redução considerável do número de células, ao mesmo tempo em que é observado o aumento destes valores para classes de dano III e IV. A maior Média da Soma dos Ranques foi encontrada para o tempo 96 horas (191.6). O Teste-U de Mann-Whitney $(\mathrm{p}<0.01)$ mostrou diferenças significativas entre todos os tempos amostrados, o que pode ser visualizado na Figura 6.

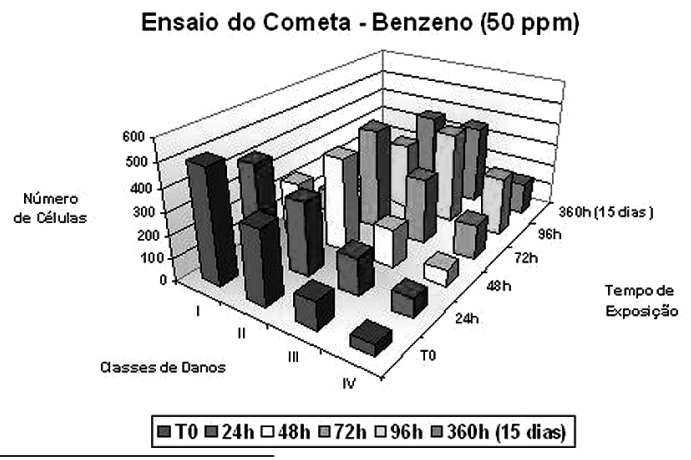

Figura 5 - Relação do número de células encontradas para cada Classe de Dano no Ensaio do Cometa em diferentes tempos de exposição ao tratamento com benzeno (50ppm).

Tabela 1- Teste do Micronúcleo em tratamento com benzeno (50ppm) mostrando a média e 0 desvio padrão nos diferentes tempos de exposição.

\begin{tabular}{ccccccc}
\hline \multicolumn{7}{c}{ Tempo de Exposição } \\
\hline Tratamento & $\mathrm{T}_{0}$ & $24 \mathrm{~h}$ & $48 \mathrm{~h}$ & $72 \mathrm{~h}$ & $96 \mathrm{~h}$ & $\begin{array}{c}360 \mathrm{~h} \\
(15 \mathrm{dias})\end{array}$ \\
$\begin{array}{c}\text { Benzeno } \\
(50 \mathrm{ppm})\end{array}$ & 0.1 & 0.2 & 0.7 & & 0.2 & 0.1 \\
$\mathrm{~N}=10$ & $( \pm 0.316)$ & $( \pm 0.422)$ & $( \pm 1.06)$ & & $( \pm 0.632)$ & $( \pm 0.316)$ \\
\hline
\end{tabular}

Tabela 2 - Médias das Classes de Dano e das Somas dos Ranques nos diferentes tempos de exposição ao tratamento com benzeno (50ppm) no Ensaio do Cometa * $p<0.01$

\begin{tabular}{|c|c|c|c|c|c|c|}
\hline \multirow{2}{*}{ Tratamento } & \multirow{2}{*}{$\begin{array}{l}\text { Tempo de } \\
\text { Exposiçãao }\end{array}$} & \multicolumn{4}{|c|}{ Média das Classes de Dano } & \multirow{2}{*}{$\begin{array}{c}\text { Média da Soma dos } \\
\text { Ranques } \\
\text { ( } \pm \text { Desv. Padrão) }\end{array}$} \\
\hline & & 1 & $\|$ & III & IV & \\
\hline \multirow{6}{*}{$\begin{array}{l}\text { Benzeno } \\
\text { (50 ppm) }\end{array}$} & $\mathrm{T}_{0}$ & 50.3 & 32.9 & 12.0 & 4.8 & $71.3( \pm 20.7)$ \\
\hline & $24 \mathrm{~h}$ & 42.3 & 32.5 & 16.5 & 8.7 & $91.6( \pm 15.2)^{\star}$ \\
\hline & $48 \mathrm{~h}$ & 26.3 & 46.1 & 19.0 & 8.6 & $109.8( \pm 15.9)^{\star}$ \\
\hline & $72 \mathrm{~h}$ & 10.2 & 45.3 & 29.1 & 15.4 & $149.7( \pm 15.7)^{\star}$ \\
\hline & $96 \mathrm{~h}$ & 2.3 & 30.3 & 40.9 & 26.5 & $191.6( \pm 16.3)^{*}$ \\
\hline & $\begin{array}{c}360 \mathrm{~h} \\
\text { (15 dias) }\end{array}$ & 3.6 & 40.2 & 40.1 & 16.1 & $168.8( \pm 18.3)^{*}$ \\
\hline
\end{tabular}




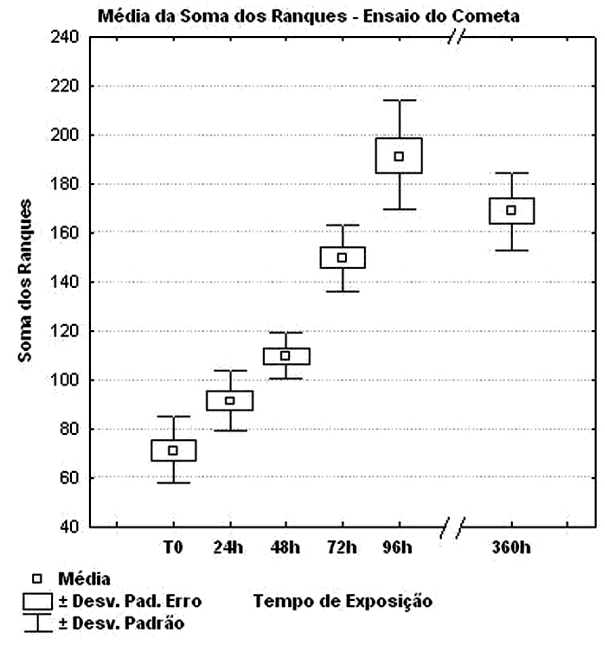

Figura 6 - Médias da Soma dos Ranques do Ensaio do Cometa para 0 tratamento com benzeno (50ppm) mostrando as diferenças significativas em relação ao $\mathrm{T}_{0}$ em todos os tempos amostrados, segundo o Teste-U de Mann-Whitney $(p<0,01)$.

\section{DISCUSSÃO}

Inúmeros testes têm sido desenvolvidos com organismos aquáticos podendo ser potencialmente usados para análise de químicos genotóxicos. O Teste do MN e o Ensaio do Cometa foram utilizados neste trabalho como ferramenta de análise xenobiótica ao benzeno, postulando uma avaliação prévia para um biomonitoramento de mananciais de água através da utilização dos peixes elétricos (Eigenmannia virescens) como biomarcadores de efeito.

Segundo Sánchez-Galán et al. (1998), os peixes são considerados bons indicadores para a detecção de contaminação de recursos hídricos por substâncias genotóxicas. Eritrócitos de sangue periférico são muito comumente usados para a aplicação do Ensaio do Cometa em conjunto com o Teste do MN, utilizando peixes como bioindicadores para avaliação ambiental de contaminação genotoxicológica (Belpaeme, et al. 1996; Da Silva et al. 2002; Russo et al. 2004; Buschini, et al.; 2004).

Os resultados apresentados para o Teste do $\mathrm{MN}$ em Eigenmannia virescens em exposição ao benzeno, mostraram que não houve diferenças significativas para nenhum dos tempos amostrados. Porém, mesmo não apresentando diferença significativa para o tempo $48 \mathrm{~h}$, é constatado um tênue aumento na freqüência de MNs (Figura 3), sugerindo que a capacidade do teste do MN em detectar determinados níveis de contaminação pode ter sido insuficiente para revelar ação genotóxica por benzeno a $50 \mathrm{ppm}$. Ou ainda, que a concentração de benzeno pode ter reduzido em virtude da capacidade volátil do benzeno, indicando uma perda na concentração inicial de benzeno. Hayashi et al. 1998, avaliando sistemas de monitoramento usando organismos aquáticos para detecção genotóxica, sugerem que a habilidade do Teste $\mathrm{MN}$ em detectar baixos níveis de contaminação deve ser melhorado.

Al-Sabti (2000) por outro lado, avaliando a genotoxidade de um corante industrial pelo Teste do MN, utilizando o benzeno a concentração de $10 \mathrm{ppm}$ como controle positivo em carpas, Carassius auratus gibelio, mostrou resultados satisfatórios para esta espécie, o que demonstra uma relativa diferença espécieespecífica para detectar danos genotóxicos em diversas espécies de organismos. Exemplificado pelo resultado de Grisolia \& Cordeiro (2000), onde três espécies de peixes apresentaram diferentes resistências expostos aos mesmos tratamentos com agentes mutagênicos.

A simplicidade e sensibilidade do Ensaio do Cometa fazem dele um sistema adequado de teste para biomonitoramento a níveis crônicos de exposição, podendo ser utilizado em inúmeras análises onde se podem avaliar células viáveis (Belpaeme et al., 1998). Além das vantagens citadas e do relativo baixo custo, o Ensaio do Cometa difere de outros ensaios que detectam danos no DNA por requerer células viáveis, mas não em divisão, permitindo, assim, sua aplicação a qualquer tipo de tecido dos quais células vivas possam ser obtidas (Collins et al., 1997; Ribeiro et al., 2003).

Em trabalho de avaliação comparada entre as duas técnicas de $\mathrm{MN}$ e Ensaio do Cometa para detectar efeitos genotóxicos da radiação de Raios-X, He et al. (2000), encontraram maior sensibilidade para avaliação de dano no DNA para o Ensaio do Cometa que para o Teste MN. Isto acarreta uma classificação de diferentes "endpoints" de avaliação genotoxicológica, ressaltando a importância de manter uma combinação de testes para melhor discernimento da mutagenicidade dos agentes e avaliação de baixas doses de efeitos.

No presente estudo, o Ensaio do Cometa apresentou diferenças significativas para todos os tempos de exposição em relação ao $\mathrm{T}_{0}$ com aumento gradual até o tempo de $96 \mathrm{~h}$, mostrando até aqui, um efeito tempo-dependente. Para o tempo de exposição de 360 horas (15 dias), apresentou um tênue aumento na média das classes de dano I e II (tabela 2) e redução para classes de dano III e IV, sugerindo a recuperação de células viáveis e/ou perda da concentração total e inicial de 50ppm de benzeno.

Conclui-se que para o Ensaio do Cometa a detecção do dano ao genoma dos exemplares expostos a 50ppm de benzeno, ocorreu apresentando diferença significativa já em $24 \mathrm{~h}$ de exposição, denotando grande sensibilidade em avaliar dano ao DNA. Por outro lado, o Teste do MN avaliado sobre as mesmas condiçōes, não apresentou diferenças significativas para nenhum dos tempos amostrados, sugerindo certa resistência de E. virescens à ação mutagênica de benzeno para efeitos aneugênicos e clastongênicos, detectados pelo teste $\mathrm{MN}$. 


\section{CONCLUSÕES}

O Teste do Micronúcleo demonstrou que não houve efeito mutagênico significante sobre os eritrócitos de Eingenmannia virescens, expostos à concentração de $50 \mathrm{ppm}$ de benzeno, para nenhum dos cinco tempos amostrados.

O Ensaio do Cometa foi eficiente para detectar efeitos genotóxicos de benzeno nos eritrócitos de Eingenmannia virescens para todos os tempos amostrados, apresentando maior sensibilidade que o Teste do MN para detectar efeitos genotóxicos para 50ppm de benzeno.

O Ensaio do Cometa mostrou um aumento gradual no número de células com maiores classes de danos de acordo com maior tempo de exposição, indicando um efeito tempodependente.

Para o monitoramento dos mananciais de água, sugere-se que o bioensaio transcorra com água proveniente do próprio local de coleta dos exemplares e a exposição ao benzeno sejam coletadas amostras dos tempos para avaliar as diferenças de concentrações.

\section{BIBLIOGRAFIA CITADA}

Al-Sabti, K. 2000. Chlorotriazine Reactive Azo Red 120 Textile Dye Induces Micronuclei in Fish. Ecotoxicology and Environmental Safety. No 47. p. 149-155.

Alves-Gomes, J.A.; Ortí, G.; Haygood, M.; Meyer, M.; Heiligenberg, W. 1995. Phylogenetic analysis of the South American electric fishes (Order Gymnotiformes) and the evolution of their electrogenic system: A synthesis based on morphology, electrophysiology, and mitochondrial sequence data. Molecular Biology Evolution 12(2): p. 298-318.

Alves-Gomes, J.A. 1997. Informaçôes preliminares sobre a bioecologia de peixes elétricos (Ordem Gymnotiformes) em Roraima. In: BARBOSA R.I.; FERREIRA E.J. \& COSTELLÓN E.G. (Eds.). Homem, ambiente e Ecologia no Estado de Roraima. Instituto Nacional de Pesquisas da Amazônia (INPA), Manaus, AM.

Belpaeme, K.; Delbeke, K.; Zhu, L.; Kirsch-Volders, M. 1996. Cytogenetic studies of PCB77 on brown trout (Salmo trutta fario) using the micronucleus test and the alkaline Comet assay. Mutagenesis. No11. p. 485-492.

Belpaeme, K.; Cooreman, K.; Kirsch-Volders, M. 1998. Development and validation of the in vivo alkaline comet assay for detecting genomic damage in marine flatfish. Mutation Research. No 415. p. 167184.

Bennett, M.V.L. 1971. Electroreception. In: Hoar, W. S. \& Randall, D. J. (Eds.) Fish Physiology, Vol. 5. New York, Academic Press. p 493-574.

Bickham, J.W.; Sandhu, S.; Hebert, P.D.N.; Chikhi, L.; Athwal, R. 2000. Effects of chemical contaminants on genetic diversity in natural populations: implications for biomonitoring and ecotoxicology. Mutation Research. No 463. p. 33-51.

Bücker, A.; Conceição, M.B. 2004. Avaliação da genotoxicidade por frequiência de Micronúcleos em eritrócitos de tilápias expostas às águas do Rio Itajaí-Açú e Itajaí-Mirim, Santa Catarina-Brasil.
In: VIII CONGRESSO BRASILEIRO DE ECOTOXICOLOGIA. Sociedade Brasileira de Ecotoxicologia - SETAC Brasil. Florianópolis, SC. Vol.2. Livro de Resumos. p 109-110.

Bullock, T.H.; Fernandes-Souza, N.; Graf, W.; Helligenberg, W.; Langner, G.; Meyer, D.L.; Pimentel-Souza, F.; Scheich, H.; Viancour, T.A. 1979. Aspectos do uso da Descarga do Órgão Elétrico e Eletrorrecepção nos Gymnotoidei e outros peixes Amazônicos. Acta Amazonica, 9 (3): 549-572.

Buschini, A.; Martino, A.; Gustavino, B.; Monfrinotti, M.; Poli, P.; Rossi, C.; Santoro, M.; Dörr, A.J.M.; Rizzoni, M. 2004. Comet assay and micronucleus test in circulating erythrocytes of Cyprinus carpio specimens exposed in situ to lake waters treated with disinfectants for potabilization. Mutation Research. No 557. p 119-129.

Campana, M.A.; Panzeri, A.M.; Moreno, V.J.; Dulout, F.N. 1999. Genotoxic evaluation of the pyrethroid lambda-cyhalothrin using the micronucleus test in erythrocytes of the fish Cheirodon interruptus interruptus. Mutation Research, n438. p.155-161.

Capela, F.S. 2001. Avaliação de Biomarcadores. Dept. de Biologia, Universidade de Évora.

Chagas, C. \& Carvalho, A. P. 1961. Bioelectrogenesis: a comparative survey of its mechanisms with particular emphasis on electric fishes. Elsevier Publishing Company. 413pp.

Collins, A.R.; Dobson, V.L.; Dusinská, M.; Kennedy, G.; Stetina, R. 1997 . The comet assay: what can it really tell us? Mutation Research. no 375. p.183-193.

CONAMA - Conselho Nacional do Meio Ambiente. 2000. Resolução $N^{\circ} 273$ - 29 de novembro de 2000. Conselho Nacional do Meio Ambiente. Brasília, DF.

Da Silva, J.; Erdtmann, B.; Henriques, J.A.P. 2003. Genética Toxicológica. Porto Alegre: Alcance, v.1. 424pp.

Da Silva, J.; Herrmann, S.M.; Heuser, V.; Peres, W.; Possa Marroni, N.; González-Gallego, J.; Erdtmann, B. 2002. Evaluation of the genotoxic effect of rutin and quercetin by comet assay and micronucleus test. Food and Chemical Toxicology. No 40. p. 941-947.

Fenech, M. 2000. The in vitro micronucleus technique. Mutation Research. no 455. p.81-95.

Fenech, M.; Cheng, W.P.; Kirsch-Volders, M.; Holland, N.; Bonassi, S.; Zeiger, E. 2003. HUMN project: detailed description of the scoring criteria for the cytokinesis-block micronucleus assay using isolated human lymphocyte cultures. Mutation Research. no 534. 65-75p.

Gonçalves, L.M.; Conceição, M.B.; Resgalla-Junior, C. 2003. Avaliação do potenial genotóxico das águas do Rio Itajaí-Açú e zona costeira sobre os hemócitos do mexilhão Perna perna através do Ensaio do Cometa. In: II SIMPÓSIO BRASILEIRO DE ENGENHARIA AMBIENTAL, 2003. Itajaí, SC. Livro de Resumos. Vol.1. Itajaí: UNIVALI, p 384.

Gontijo, Á.M.M.C., Barreto, R.E., Speit, G., Reyes, V.A.V., Volpato, G.L., Salvadori, D.M.F. 2003. Anesthesia of fish with benzocaine does not interfere with comet assay results. Mutation Research. No 534. p. 165-172.

Grisolia, C.K. 2002. A comparison between mouse and fish micronucleus test using cyclophosphamide, mitomycin $C$ and various pesticides. Mutation Research. No 518. p. 145-150. 
Grisolia, C.K.; Cordeiro, C.M.T. 2000. Variability in micronucleus induction with different mutagens applied to several species of fish. Genetics and Molecular Biology. No 23 (1). p. 235-239.

Hayashi M.; Ueda T.; Uyeno K.; Wada K.; Kinae N.; Saotome K.; Tanaka N.; Takai A.; Sasaki Y.F.; Asano N.; Sofuni T.; Ojima Y. 1998. Development of genotoxicity assay systems that use aquatic organisms. Mutation Research. No 399. p. 125-133.

Hartmann, A.; Agurell, E.; Beevers, C.; Brendler-Schwaab, S.; Burlinson, B.; Clay, P.; Collins, A.; Smith, A.; Speit, G.; Thybaud, V.; Tice, R.R. 2003. Recommendations for conducting the in vivo alkaline Comet assay. Mutagenesis. Vol. 18 (1). p. 45-51.

He, J.L.; Chen, W.L.; Jin, L.F.; Jin, H.Y. 2000. Comparative evaluation of the in vitro micronucleus test and the comet assay for the detection of genotoxic effects of $X$-ray radiation. Mutation Research. No 469. p. 223-231.

IARC - International Agency for Research on Cancer. 2003. Monographs on the Evaluation of Carcinogenic Risks to Humans. Disponível em: <http://www.iarc.fr>. Acesso em: 25 dez. 2003.

Kramer, B. 1999. Mechanisms of Signal Analysis in Eingenmannia (Gymnotiformes): The Jamming Avoidance Response and Communication. In: Val, A.L.; Almeida-Val, V.M.F. (Eds). Biology of Tropical Fishes. Instituto Nacional de Pesquisas da Amazônia (INPA), Manaus-AM. p. 41-62.

Porto, J.I.R.; Araújo, C.S.O.; Feldberg, E. 2005. Mutagenic effects of mercury pollution as revealed by micronucleus testo $n$ three Amazonian fish species. Environmental Research. No 97. p. 287-292.

Ribeiro, L.R.; Salvadori, D.M.F.; Marques, E.K. 2003. Mutagênese Ambiental. Editora da ULBRA. Canoas-RS. 356pp.

Rossoni, D.M. 2005. A utilização das descargas dos órgãos elétricos de Apteronotus hasemani e Apteronotus bonapartii (ApteronotidaeGymnotiformes) como bioindicadores em ambientes aquáticos. Manaus: INPA. Dissertação de Mestrado. 86pp.
Russo, C.; Lucia, R.; Morescalchi, M.A.; Stingo, V. 2004. Assessment of environmental stress by the micronucleus test and the Comet assay on the genome of teleost populations from two natural enviranments. Ecotoxicology and Environmental Safety. No 57. p. 168-174.

Sánchez-Galán, S.; Linde, A.R.; Izquierdo, J.I.; García-Vásquez, E. 1998. Micronuclei and fluctuating asymmetry in brown trout (Salmo trutta): complementary methods to biomonitor freshwater ecosystems. Mutation Research. No 412. p. 219-225.

Schmid, W. 1976. The micronucleus test for cytogenetics analysia. In: Principles and Methods for Their Detection (ed. Hollaender,A.). Plenum Press, New York, Vol.4, p.31-53.

Shugart, L.R.; Adams, S.M.; Jiminez, B.D.; Talmage, S.S.; McCarthy, J.F. 1989. Biological markers to study exposure in animals and bioavailability of environmental contaminants. Biological Monitoring for Pesticide Exposure. American Chemical Society. Washington-DC.

Singh, N.P.; McCoy, M.T.; Tice, R.R.; Schneider, E.L. 1988. A simple technique for quantitation of low levels of DNA damage in individual cells. Exp Cell Res. no 175. p. 184-191.

Valent, G.U. 1998. Histórico da importância e utilização dos testes de genotoxicidade no Brasil. In: CONGRESSO DE ECOTOXICOLOGIA. Itajaí-SC.

Zagatto, P.A. 1998. Significado dos estudos de validação de testes de toxicidade: resultados publicados. In: CONGRESSO DE ECOTOXICOLOGIA. Itajaí-SC.

White, P.A.; Rasmussen, J.B. 1998. The genotoxic hazards of domestic wastes in surface waters. Mutation Research. No 410. p. 223-236.

W.H.O. World Health Organization. 1993. International Program on Chemical Safety (IPCS). Environmental Health Criteria 155. Biomarkers and Risk Assessment: Concepts and Principles. Geneva.

Recebido em 29/08/2005

Aceito em 11/05/2006 
